\title{
PUBLIC HEALTH DENTISTS AND DENTAL HYGIENISTS EXPRESS AN INTEREST IN CONTINUING EDUCATION
}

\author{
By Joan M. Keevil, RDH, MPH*
}

The writer of this report has gathered information that should be useful to those engaged in planning continuing education for personnel practicing dental public health.

In July 1969, the Unit in Dental Public Health of the School of Public Health at the University of Michigan mailed out a questionnaire to 281 dentists and 23 dental hygienists, all currently engaged in the practice of public health. The purpose of the survey was twofold: (1) to determine the interest in, and the need for continuing education, as expressed by personnel now practicing dental public health, and (2) to gather dat that could be used in planning the courses for continuing education in this specialty.

\section{Method of Obtaining Information}

The questionnaire was designed to determine the recipients' professional interest in attending a course of continuing education, and their preferences for content, format, and length of such a course, the time of year that it should be offered, and the size of the group that might be enrolled. Additional suggestions or comments were solicited.**

The population surveyed was limited to those dentists and dental hygienists who had prepared themselves in public health at the graduate level. Included in the study werc graduates in dental public health or dental health education at the University of Michigan, and all diplomates of the American Board of Dental Public Health. The mailing-lists of the American Association of Public Health Dentists and the American Public Health Association were utilized to obtain additional names of dentists and dental hygienists engaged in the practice of public health at the federal, state, and local levels and those engaged in teaching dental public health or community dentistry. No attempt was made, however, to obtain equal numbers of public health dentists for representing the various levels of practice.

\section{Findings}

Of the 304 individuals mailed the questionnairc, 194 or 64 percent, responded by filling out and returning it. While developing the questionnaire, it seemed desirable to gain candid responses from the participants, hence, signature by the respondent was left optional. It was not feasible, therefore. to send out a second mailing to obtain a larger percentage of responses.

Of the 194 individuals who responded, 153 or 79 percent expressed an interest in attending a course of continuing education in 1970-71. Sixteen respondents indicated that they would not be interested in attending a course, and two responded "possibly." Twenty-two respondents did not answer this question.

For the next reaction, a list of 10 possible subjects for a course was submitted. Respondents were asked to select the five subjects that they would like most to have

\footnotetext{
+ Instructor in Dental Public Health, School of Public Health, and Instructor in Community Den tistry. School of Dentistry, University of Michigan, Ann Arbor. Michigan, 48104.

* A copy of the questionnaire will be mailed un request.
} 
covered and rank their choices one to five. The subjects receiving the largest total number of votes were:

Behavioral sciences as related to dental public health $\ldots \ldots \ldots 111$

Evaluation of dental public health practice .......... 106

Control of quality in programs of dental care . . . . . . . 103

Dental public health aspects of recent federal legislation .....95

Design of research, its methodology, and grantsmanship ..... 92

Cost/benefit analysis and performance-budgeting . . . . . . 89

The weighted responses (five points for first priority, four points for second priority ... one point for fifth priority) effected minor changes in the ranking of the subjects:

Evaluation of the practice of dental public health . . . . . 362

Behavioral sciences as related to dental public health . . . . . . . . . . . . . .

Control of quality in programs of dental care . . . . . . . . 314

Cost/benefit analysis and performance-budgeting ....... 312

Dental public health aspects of recent federal legislation . . . 270

Design of research, its methodology, and grantsmanship . . . . 269

The subjects receiving the largest number of votes as priority one were:

Behavioral sciences as related to dental public health . . . . . 31

Evaluation of the practice of dental public health . . . . . . . 29

Cost/benefit analysis and performance-budgeting . . . . . . 27

Control of quality in programs of dental care . . . . . . . 20

Oral epidemiology and clinical trials . . . . . . . . . . 17

Design of research, its methodology, and grantsmanship . . . . 17

The respondents also were asked to list any other subjects that they would like to have reviewed. Approximately 30 additional subjects were listed but none appeared more than once, hence, further analysis was unnecessary. Ten persons did not respond to the question; and nine did not indicate their choices numerically, hence their responses could not be tabulated.

The third question asked the respondents to indicate the type of format that they would prefer. A majority of 61 percent (118) indicated that they would prefer a combination of lectures and seminars. Twenty-eight (14 percent) indicated that they would prefer a workshop. The remaining respondents indicated a preference for lectures, or seminars, or some combination of approaches. Eleven did not respond to the question.

The respondents next were asked how long a course they would prefer-two days, three days, one week, two weeks, or other. Eighty-five individuals (44 percent) indicated that they would prefer a course of one week in duration; 58 (30 percent) expressed preference for a course of three days in length; 21 indicated that the course should be two weeks or longer; four stated that length would depend upon the topic; and the remainder preferred less than three days or responded by selecting a combination of answers. Thirteen individuals did not respond to the question.

In regard to the time of year, 64 persons ( 33 percent) preferred that the course be offered during the summer. The second largest group, 49 respondents (25 percent), preferred spring. Fewest preferred winter. Twenty-two individuals did not answer or express a preference.

Then a question was asked regarding the size of the enrolled group. A substantial majority of 156 persons ( 80 percent) expressed a preference for limiting the size of enrollment. Eighteen individuals did not respond to the question.

Lastly, the respondents were asked if they has any additional suggestions or comments. Five suggested that a series of courses should be offered on a continuing 
annual basis with different subjects covered at each course. Several suggested that participants should have similar levels of training and experience and be engaged in a similar type of public health practice. Another suggested that the course should not be limited to dentists and dental hygienists but should include others who are employed in responsible positions in the practice of dental public health.

Three suggested that participants be provided with a list of pertinent references to be studied in advance of the course. Several expressed a desire for the proceedings to be published. sent to participants, and made available to others interested in the subject who where unable to attend. Several suggested a need for any proposed course in continuing education to be coordinated with present offerings such as those of the University of North Carolina, School of Public Health.

Another respondent suggested that continuing education should be geared to problem-solving. Still another respondent suggested that participants submit current problems from actual "real-practice situations" that could be subjected to "groupthinking." Three persons stated that at least a portion of the student's cost for the course should be financed by some type of training grant.

\section{Summarizing}

Over three-fourths of the responding public health dentists and dental hygienists, surveyed in regard to their interest in continuing education, expressed a desire to attend such a course in the early future. They would like the course to cover one subject, preferably behavioral sciences as related to dental public health or methods of evaluating the practice of dental public health. They would prefer the course to be one week in length, to be a combination of lectures and seminars, to be presented during the summer, and to have the number of enrollees limited. They would like at least a portion of the participant's cost financed by a training grant.

\section{Come Out of Hiding}

Today's dentist must reach beyond his office and his operating room and add his intellectual vigor to the community of man. He cannot afford to stand aside from the wave of social consciousness now sweeping through the middle third of the Twentieth Century. He must accept special obligations because of his education, ability, and potential for leadership. The dentist's training and his disciplined mind fit him to solve some of the problems that have defied answers until now. He no longer can spend a lifetime in the confines of his private office and limit his services to those fellowmen who seck him. (Arthur Snider in the 1969 Conference on Journalism)

\section{At the Health Counter}

Many a man, impressed by the fearsome data on the dangers of smoking cigarettes, turns to a pipe or cigars. So, what happens? The Maryland Dental Association, during its convention, comes out with the warning, "Oral cancer is rising from the hazards to health in smoking pipes and cigars." (Louis Azrael in the Baltimore News-American) 